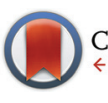

CrossMark \& click for updates

Cite this: Polym. Chem., 2015, 6 , 4624

Received 18th March 2015, Accepted 11th May 2015

DOI: $10.1039 / \mathrm{c} 5$ py00394f

www.rsc.org/polymers

\section{Pyrrolo[3,4-g]quinoxaline-6,8-dione-based conjugated copolymers for bulk heterojunction solar cells with high photovoltages $\uparrow$}

\author{
Xiaofeng Xu, $\star^{\mathrm{a}}$ Chuanfei Wang, $\neq^{\mathrm{b}}$ Olof Bäcke, ${ }^{\mathrm{c}}$ David I. James, ${ }^{\mathrm{a}}$ Kim Bini, ${ }^{\mathrm{a}}$ \\ Eva Olsson, ${ }^{c}$ Mats R. Andersson, ${ }^{a, d}$ Mats Fahlman ${ }^{b}$ and Ergang Wang*a
}

\begin{abstract}
A new electron-deficient building block 5,9-di(thiophen-2-yl)-6H-pyrrolo[3,4-g]quinoxaline-6,8(7H)dione (PQD) was synthesized via functionalizing the 6- and 7-positions of quinoxaline (Qx) with a dicarboxylic imide moiety. Side chain substitution on the PQD unit leads to good solubility which enables very high molecular weight copolymers to be attained. The fusion of two strong electron-withdrawing groups ( $Q x$ and dicarboxylic imide) makes the PQD unit a stronger electron-deficient moiety than if the unit had just one electron-withdrawing group, thus enhancing the intramolecular charge transfer between electron-rich and deficient units of the copolymer. Four PQD-based polymers were synthesized which feature deep-lying highest occupied molecular orbital (HOMO) levels and bathochromic absorption spectra when compared to PBDT-Qx and PBDT-TPD analogues. The copolymers incorporated with benzo[1,2- $\left.b: 4,5-b^{\prime}\right]$ dithiophene (BDT) units show that the $1 \mathrm{D}$ and $2 \mathrm{D}$ structural variations of the side groups on the BDT unit are correlated with the device performance. As a result, the corresponding solar cells (ITO/PEDOT:PSS/polymer:PC 71 $_{71} \mathrm{BM} / \mathrm{LiF} / \mathrm{Al}$ ) based on the four copolymers feature very high opencircuit voltages $\left(V_{o c}\right)$ of around $1.0 \mathrm{~V}$. The copolymer PBDT-PQD1 attains the best power conversion efficiency of $4.9 \%$, owing to its relatively high absorption intensity and suitable film morphology. The structure-property correlation demonstrates that the new PQD unit is a promising electron-deficient building block for efficient photovoltaic materials with high $V_{\text {oc. }}$.
\end{abstract}

\section{Introduction}

Polymer solar cells (PSCs) have attracted considerable attention over the past decade due to their unique advantages of flexible, light weight, and the ability to be manufactured on a large-scale at low cost. ${ }^{1-4}$ The PSC based on the bulk-heterojunction (BHJ) concept, which uses a solution-processed active layer incorporating an electron-donor and an electron-acceptor, is a promising device structure for achieving high power conversion efficiency (PCE). ${ }^{5}$ Conjugated D-A copolymers,

\footnotetext{
${ }^{a}$ Department of Chemistry and Chemical Engineering, Chalmers University of Technology, SE-412 96 Göteborg, Sweden. E-mail: ergang@chalmers.se ${ }^{b}$ Division of Surface Physics and Chemistry, IFM, Linköping University, SE-581 83 Linköping, Sweden

${ }^{c}$ Department of Applied Physics, Chalmers University of Technology, SE-412 96 Göteborg, Sweden

${ }^{d}$ Ian Wark Research Institute, University of South Australia, Mawson Lakes, South Australia 5095, Australia

$\dagger$ Electronic supplementary information (ESI) available: Size exclusion chromatography (SEC) measurement, cyclic voltammetry (CV) measurement, and ${ }^{1} \mathrm{H}$ and

${ }^{13}$ C NMR spectra of the compounds. See DOI: 10.1039/c5py00394f

$\$$ These authors contributed equally to this work.
}

obtained by combining alternately an electron-donating (D) and an electron-withdrawing (A) moiety, are particularly promising electron-donor candidates. Judicious selection of $\mathrm{D}$ and A moieties can tailor the $\mathrm{D}-\mathrm{A}$ interaction and $\pi$-electron delocalization, to achieve tunable band gaps and energy levels, which should match well with the frequently used fullerene derivatives as the electron-acceptor. ${ }^{6-9}$ Early D-A copolymers were composed of simple arenes like commercially available fluorene and carbazole units. ${ }^{10-13}$ Presently, increasing efforts are being made to synthesize new fused arenes to construct various medium and low band gap copolymers for higher photovoltaic performances. For the electron-withdrawing units, introduction of fused rings with several electrondeficient groups or strongly electronegative atoms has been proven to be effective. To date, several successful building blocks have been identified, such as 2,1,3-benzothiadiazole (BT),${ }^{14-16}$ quinoxaline (Qx), ${ }^{17-19}$ pyrrolo[3,4-c]-pyrrole1,4-dione (DPP) ${ }^{20,21}$ thieno[3,4-c]pyrrole-4,6-dione (TPD) ${ }^{22-24}$ and isoindigo. ${ }^{25-28}$

In our previous work, we have found that $\mathrm{Qx}$ is an easily synthesized A unit for high-performance D-A copolymers. ${ }^{11,29,30}$ Compared to the BT unit, the Qx unit has a 
slightly weaker electron-withdrawing ability. But unlike the BT unit, the Qx unit has pendant alkoxyphenyl or alkylthienyl side groups which can extend the $\pi$-electron delocalization and improve the solubility of the conjugated backbones. ${ }^{33}$ Using the Qx unit, the copolymer TQ1 has achieved a high opencircuit voltage $\left(V_{\mathrm{oc}}\right)$ of $0.9 \mathrm{~V}$ and a high PCE of $6 \% .{ }^{17}$ Recently, we synthesized a series of indacenodithiophene-quinoxaline copolymers. The corresponding non-fluorinated copolymer PIDTTQ-m attained a PCE as high as $7.8 \%$, which represents one of the highest efficiencies for electron-donor copolymers with band gaps over $1.75 \mathrm{eV} .^{22}$ Another frequently used acceptor unit is thieno[3,4-c]pyrrole-4,6-dione (TPD), which is a simple and symmetrical building block for various high band gap conjugated copolymers. TPD based D-A copolymers usually have deep-lying HOMO levels. ${ }^{31}$ Various side chain substitutions on the pyrrole ring can alter the solubility and molecular self-assembly of TPD based copolymers, which has a significant effect on the charge transporting properties and the device performance. ${ }^{32-34}$ As for electron-donating comonomers, benzo[1,2- $\left.b: 4,5-b^{\prime}\right]$ dithiophene (BDT) is one of the most commonly used moieties in D-A photovoltaic materials. ${ }^{35,36}$ Through the incorporation of the Qx or TPD with the BDT unit, respectively, the copolymers BDT-Qx and BDT-TPD showed high $V_{\text {oc }}$ in the range of 0.8-0.9 V. In both copolymer systems, the structural variations of the side chain substituents on the BDT unit have been found to correlate with the device performance. These copolymers have achieved PCEs in the range of $3 \%$ to $7 \% .^{37-42}$

To date, several strong electron-deficient motifs like benzobis(thiadiazole), ${ }^{4,44}$ thiadiazoloquinoxaline, ${ }^{45,46}$ pyrazinoquinoxalines ${ }^{47,48}$ thiadiazolobenzotriazole $e^{49,50}$ and benzothiadiazole-5,6-dicarboxylic imide (DI), ${ }^{51}$ which combine two electron-withdrawing groups together, have been synthesized and characterized for optical, photovoltaic and near-infrared photodetector applications. (Scheme 1) The two fused electronwithdrawing groups can afford a stronger electron-deficient

Strong electron-deficient units with two electron-withdrawing rings

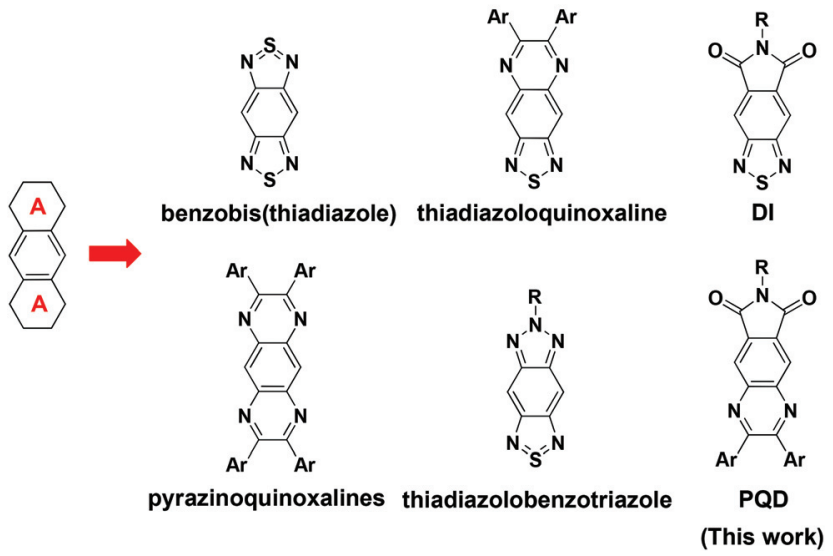

Scheme 1 Schematic illustrations and chemical structures of the electron-deficient units. moiety, thus enhancing the $\mathrm{D} / \mathrm{A}$ interaction. The enhanced molecular orbital hybridization results in a lower band gap and better spectral overlap with the solar spectrum. Using this design strategy, one novel D-A copolymer incorporating $N$-alkyl-4,7-di(thien-2-yl)-2,1,3-benzothiadiazole-5,6-dicarboxylic imide (DI) has been synthesized. ${ }^{52,53}$ One of the resulting PSCs exhibited a high $V_{\mathrm{oc}}$ of $0.91 \mathrm{~V}$ and a PCE of $5.2 \% .^{52}$ Very recently, a copolymer consisting of an alternative benzo[1,2-b:3,4- $\left.b^{\prime}: 5,6-d^{\prime}\right]$ trithiophene and 2,1,3-benzothiadiazole-5,6dicarboxylic imide backbone attained a $V_{\mathrm{oc}}$ of $0.80 \mathrm{~V}$ and a PCE of $8.3 \% .^{54}$

Inspired by the previous work mentioned above, here we intend to integrate the Qx and TPD unit together, combining the free 6- and 7-positions of the Qx motif with the 5,6-dicarboxylic imide group, to afford a new monomer 5,9-di(thiophen-2-yl)-6H-pyrrolo[3,4-g] quinoxaline-6,8(7H)-dione (PQD). The strong electron-withdrawing groups of the imide functionality should effectively reduce the electron density in the heterocyclic arene and decrease the frontier energy levels via pulling $\pi$-electrons out of the conjugated backbone. Thus, new copolymers based on the PQD unit would have low-lying HOMO levels and bathochromic absorption spectra. Importantly, the Qx moiety provides a site for meta-alkyl substitution onto its pendant phenyl groups, meaning that the PQD containing copolymers will have enough alkyl chain density to be sufficiently soluble and thus be processable. In this work, four PQD-based copolymers comprising BDT and thiophene as the electron-donors are synthesized and characterized. The electron-rich BDT and thiophene units modulate the band gaps and energy levels of PQD-based copolymers. The UV-Vis absorption, electrochemical properties, film morphology and photovoltaic performances of the copolymers are evaluated. As anticipated, the BHJ PSCs based on the four copolymers feature very high $V_{\mathrm{oc}} \mathrm{S}$ of around $1.0 \mathrm{~V}$. The PBDT-PQD1: $\mathrm{PC}_{71} \mathrm{BM}$ device attains the highest PCE of $4.9 \%$. Characterization of the side chain and backbone modulations, photoresponse and film morphology indicate a rational correlation with the device performance for these four PQD-based copolymers.

\section{Experimental section}

\section{Characterization}

${ }^{1} \mathrm{H}$ NMR (400 MHz) and ${ }^{13} \mathrm{C}$ NMR (100 MHz) spectra were recorded on a Varian Inova $400 \mathrm{MHz}$ NMR spectrometer with tetramethylsilane (TMS) as the internal reference. Matrix assisted laser desorption ionization time of flight (MALDITOF) was measured on a Bruker Autoflex Speed spectrometer. Size exclusion chromatography (SEC) was carried out on an Agilent PL-GPC 220 Integrated High Temperature GPC/SEC System with refractive index and viscometer detectors. The columns are 3 PLgel $10 \mu \mathrm{m}$ MIXED-B LS $300 \times 7.5 \mathrm{~mm}$ columns. The eluent was 1,2,4-trichlorobenzene at $150{ }^{\circ} \mathrm{C}$. Molecular weights were calculated according to relative calibration with polystyrene standards. UV-Vis absorption spectra 
were measured with a Perkin Elmer Lambda 900 UV-Vis-NIR absorption spectrometer. Square wave voltammetry (SWV) and cyclic voltammetry (CV) measurements were carried out on a CH-Instruments 650A Electrochemical Workstation. A $0.1 \mathrm{M}$ nitrogen-saturated solution of tetrabutylammonium hexafluorophosphate $\left(\mathrm{Bu}_{4} \mathrm{NPF}_{6}\right)$ in anhydrous acetonitrile was used as the supporting electrolyte. Platinum wires were used as the working electrode and counter electrode. $\mathrm{Ag} / \mathrm{Ag}^{+}$was used as the reference electrode. Potentials were referenced to the ferrocenium/ferrocene $\left(\mathrm{Fe} / \mathrm{Fe}^{+}\right)$couple by using ferrocene as an internal standard. The copolymer films were deposited onto the working electrode from a chloroform solution. Tappingmode atomic force microscopy (AFM) was carried out using a Digital Instrument Dimension 3000 with a G-type scanner and a standard silicon tip. Transmission electron microscopy (TEM) was performed with a FEI Tecnai T20 $\left(\mathrm{LaB}_{6}, 200 \mathrm{kV}\right)$. Without LiF/Al electrode deposition, the active layer was placed onto a copper grid after dissolving the PEDOT:PSS in water. The samples were dried at room temperature.

\section{Synthesis}

All the starting materials and reagents were purchased from commercial sources and used without further purification, unless otherwise mentioned. All reactions involving air-sensitive reagents were performed under a nitrogen atmosphere. Compounds $\mathbf{4}$ and $\mathbf{8}$ were prepared according to literature procedures. $^{52,55}$

7-(2-Ethylhexyl)-2,3-bis(3-(octyloxy)phenyl)-5,9-di(thiophen2-yl)-6H-pyrrolo[3,4-g]quinoxaline-6,8(7H)-dione (11). Zinc powder $(1.31 \mathrm{~g}, 20.0 \mathrm{mmol})$ was added to a solution of compound 8 (1.93 $\mathrm{g}, 4.0 \mathrm{mmol})$ in acetic acid $(40 \mathrm{~mL})$. The mixture was heated at $80^{\circ} \mathrm{C}$ for $1 \mathrm{~h}$. After cooling to room temperature, the excess amount of zinc powder was removed via filtration. The crude compound $\mathbf{9}$ in a solution of acetic acid was used for the next step without further purification. Diketone compound 10 (1.87 g, $4.0 \mathrm{mmol})$ was added to the solution and the mixture was heated at $80{ }^{\circ} \mathrm{C}$ overnight. After cooling to room temperature, the organic layer was extracted with dichloromethane $(100 \mathrm{~mL})$, washed successively with $1 \mathrm{M}$ $\mathrm{K}_{2} \mathrm{CO}_{3}$ aqueous solution and then dried over anhydrous $\mathrm{MgSO}_{4}$. The residue was purified by column chromatography with $1: 10(\mathrm{v} / \mathrm{v})$ ethyl acetate/hexane as the eluent to give the final compound as a yellow solid $(2.05 \mathrm{~g}, 58 \%) .{ }^{1} \mathrm{H}$ NMR $\left(400 \mathrm{MHz}, \mathrm{CDCl}_{3}\right), \delta(\mathrm{ppm}): 7.75(\mathrm{~d}, J=4.0 \mathrm{~Hz}, 2 \mathrm{H}), 7.71(\mathrm{~d}, J=$ $4.0 \mathrm{~Hz}, 2 \mathrm{H}), 7.36(\mathrm{~s}, 2 \mathrm{H}), 7.27(\mathrm{~m}, 2 \mathrm{H}), 7.18(\mathrm{~m}, 4 \mathrm{H}), 6.93$ $(\mathrm{m}, 2 \mathrm{H}), 3.88(\mathrm{t}, J=6.0 \mathrm{~Hz}, 4 \mathrm{H}), 3.63(\mathrm{t}, J=8.0 \mathrm{~Hz}, 2 \mathrm{H}), 1.91$ $(\mathrm{s}, 1 \mathrm{H}), 1.74(\mathrm{~m}, 4 \mathrm{H}), 1.33(\mathrm{~m}, 28 \mathrm{H}), 0.89(\mathrm{~m}, 12 \mathrm{H}) .{ }^{13} \mathrm{C}$ NMR (100 MHz, $\mathrm{CDCl}_{3}$ ), $\delta$ (ppm): 166.4, 159.1, 152.7, 141.0, 138.9, $132.8,132.5,131.1,130.0,129.2$, 127.1, 126.2, 122.7, 117.3, 115.3, 68.1, 42.7, 38.1, 31.9, 30.7, 29.3, 29.3, 29.1, 28.6, 26.1, 24.0, 23.1, 22.7, 14.1, 14.1, 10.5. MS (MALDI-TOF, $\mathrm{m} / \mathrm{z}$ ): $\left[\mathrm{M}^{+}\right]$calc: 883.44 , found: 883.15 .

5,9-Bis(5-bromothiophen-2-yl)-7-(2-ethylhexyl)-2,3-bis(3(octyloxy)phenyl)-6H-pyrrolo[3,4-g] quinoxaline-6,8 $(7 \mathrm{H})$-dione (M1). $N$-Bromosuccinimide (NBS) $(0.47 \mathrm{~g}, 2.6 \mathrm{mmol})$ in $5 \mathrm{~mL}$ of anhydrous THF was added dropwise into compound 11
(1.06 g, $1.2 \mathrm{mmol})$ in $30 \mathrm{~mL}$ of anhydrous THF. The reaction mixture was stirred at room temperature in the dark overnight. The resulting mixture was poured into ice water. The organic layer was extracted with dichloromethane $(50 \mathrm{~mL})$, washed successively with a $1 \mathrm{M} \mathrm{Na}_{2} \mathrm{~S}_{2} \mathrm{O}_{3}$ aqueous solution, and then dried over anhydrous $\mathrm{MgSO}_{4}$. The residue was purified by column chromatography with $1: 15(\mathrm{v} / \mathrm{v})$ ethyl acetate/hexane as the eluent to give the final compound as an orange solid $(1.18 \mathrm{~g}$, 95\%). ${ }^{1} \mathrm{H}$ NMR (400 MHz, $\mathrm{CDCl}_{3}$ ), $\delta(\mathrm{ppm}): 7.65(\mathrm{~m}, 2 \mathrm{H}), 7.54$ $(\mathrm{s}, 2 \mathrm{H}), 7.22(\mathrm{~m}, 4 \mathrm{H}), 7.09(\mathrm{~d}, J=8.0 \mathrm{~Hz}, 2 \mathrm{H}), 6.98(\mathrm{~d}, J=$ $8.0 \mathrm{~Hz}, 2 \mathrm{H}), 4.02(\mathrm{t}, J=6.0 \mathrm{~Hz}, 4 \mathrm{H}), 3.65$ (t, $J=8.0 \mathrm{~Hz}, 2 \mathrm{H}), 1.90$ $(\mathrm{s}, 1 \mathrm{H}), 1.81(\mathrm{~m}, 4 \mathrm{H}), 1.35(\mathrm{~m}, 28 \mathrm{H}), 0.92(\mathrm{~m}, 12 \mathrm{H}) .{ }^{13} \mathrm{C} \mathrm{NMR}$ (100 MHz, $\left.\mathrm{CDCl}_{3}\right), \delta$ (ppm): 166.3, 159.4, 153.0, 140.2, 138.5, $133.7,132.2$, 131.4, 129.2, 129.0, 126.9, 122.8, 118.5, 118.0, 114.9, 68.2, 42.8, 38.1, 31.9, 30.7, 29.4, 29.3, 28.6, 26.9, 26.2, 24.0, 23.1, 22.7, 14.1, 14.1, 10.5. MS (MALDI-TOF, $m / z$ ): $\left[\mathrm{M}^{+}\right]$calc: 1039.26 , found: 1039.04 .

\section{General procedure for polymerization}

$0.15 \mathrm{mmol}$ of dibrominated monomer, $0.15 \mathrm{mmol}$ of distannylated monomer, tris(dibenzylideneacetone)dipalladium(0) $\left(\mathrm{Pd}_{2}(\mathrm{dba})_{3}\right)(2.75 \mathrm{mg})$ and tri $(o$-tolyl $)$ phosphine $\left(\mathrm{P}(o \text {-Tol })_{3}\right)$ (3.65 mg) were dissolved in anhydrous toluene $(12 \mathrm{~mL})$ under a nitrogen atmosphere. The reaction mixture was refluxed with vigorous stirring for $48 \mathrm{~h}$. After cooling to room temperature, the copolymer was precipitated by pouring the solution into acetone and was collected by filtration through a $0.45 \mu \mathrm{m}$ Teflon filter. Then the polymer was washed in a Soxhlet extractor with acetone, diethyl ether and chloroform. The chloroform fraction was purified by passing it though a short silica gel column and then precipitated from diethyl ether. Finally, the copolymer was obtained by filtration through a $0.45 \mu \mathrm{m}$ Teflon filter and dried under vacuum at $40^{\circ} \mathrm{C}$ overnight.

Polymer PBDT-PQD1. 208 mg. Yield: 64\%. Molecular weight: $M_{\mathrm{n}}=113.4 \mathrm{kDa} ; M_{\mathrm{w}} / M_{\mathrm{n}}=2.5$.

Polymer PBDT-PQD2. 183 mg. Yield: 63\%. Molecular weight: $M_{\mathrm{n}}=98.4 \mathrm{kDa} ; M_{\mathrm{w}} / M_{\mathrm{n}}=3.6$.

Polymer PBDT-PQD3. 156 mg. Yield: 57\%. Molecular weight: $M_{\mathrm{n}}=179.1 \mathrm{kDa} ; M_{\mathrm{w}} / M_{\mathrm{n}}=3.2$.

Polymer PT-PQD. $75 \mathrm{mg}$. Yield: 35\%. Molecular weight: $M_{\mathrm{n}}=30.9 \mathrm{kDa} ; M_{\mathrm{w}} / M_{\mathrm{n}}=4.3$.

\section{PSC fabrication and characterization}

The structure of the polymer solar cell was glass/ITO/PEDOT: PSS/polymer:PC ${ }_{71} \mathrm{BM} / \mathrm{LiF} / \mathrm{Al}$. As a buffer layer, PEDOT:PSS (Baytron P VP Al 4083) was spin-coated onto ITO-coated glass substrates, followed by annealing at $150{ }^{\circ} \mathrm{C}$ for 15 minutes to remove the water. The thickness of the PEDOT:PSS layer was around $40 \mathrm{~nm}$, as determined by a Dektak $6 \mathrm{M}$ surface profilometer. The active layer, consisting of a copolymer and $\mathrm{PC}_{71} \mathrm{BM}$ blend, was spin-coated from $o$-dichlorobenzene (oDCB) solution onto the PEDOT:PSS layer. The spin-coating was done in a glove box and the prepared active layers were directly transferred to a vapor deposition system mounted inside of the glove box. LiF (0.6 nm) and Al (100 nm) were used as the top electrodes, and deposited via a mask under 
vacuum onto the active layer. The accurate area of every device $\left(4.5 \mathrm{~mm}^{2}\right)$, defined by the overlap of the ITO and metal electrode, was measured using a microscope. The PCEs were calculated from the $J-V$ characteristics recorded by a Keithley 2400 source meter under the illumination of an AM 1.5G solar simulator with an intensity of $100 \mathrm{~mW} \mathrm{~cm}^{-2}$ (Model SS-50A, Photo Emission Tech., Inc.). The light intensity was determined using a standard silicon photodiode. EQEs were calculated from the photocurrents under short-circuit conditions. The currents were recorded using a Keithley 485 picoammeter under monochromatic light (MS257) illumination through the ITO side of the devices.

\section{Results and discussion}

\section{Synthesis of monomers and polymers}

The synthetic routes of the monomers are illustrated in Scheme 2. Reduction of compound $\mathbf{8}$ was first attempted using the mild reductant $\mathrm{NaBH}_{4}$, however, the attempt failed to give the desired diamine 9. A stronger reductant, $\mathrm{Zn}$ powder, turned out to be the appropriate reductant. Compound $\mathbf{8}$ was reduced with zinc powder in glacial acetic acid to afford intermediate compound $\mathbf{9}$. Since the diamine groups are not stable in air, compound $\mathbf{9}$ was condensed immediately with the diketone compound $\mathbf{1 0}$ to obtain compound $\mathbf{1 1}$ in a moderate yield of $58 \%$. Next, the bromination of compound 11 with NBS provided monomer M1 in a high yield of 95\%. The chemical structures of all the compounds were confirmed using ${ }^{1} \mathrm{H}$ $\mathrm{NMR},{ }^{13} \mathrm{C}$ NMR and MALDI-TOF measurement (see the Experimental section for details).

Scheme 3 shows the synthetic routes for the copolymers. The polymerizations were carried out using $\mathrm{Pd}_{2}(\mathrm{dba})_{3}$-catalyzed Stille coupling of the corresponding distannylated monomers and dibrominated monomer M1 (PQD), respectively. The same reaction time for polymerization ( $48 \mathrm{~h}$ ) was used for each copolymer. After polymerization, the crude copolymers were washed using Soxhlet extraction with acetone and diethyl ether for $24 \mathrm{~h}$ each. Subsequently, the copolymers were Soxhletextracted with chloroform. The molecular weights of the four copolymers were measured using size exclusion chromatography (SEC) at $150{ }^{\circ} \mathrm{C}$, using 1,2,4-trichlorobenzene as the eluent. The series of BDT-PQD copolymers were obtained with very high molecular weights and a moderate range of polydispersity index (PDI). The number-average molecular weights $\left(M_{\mathrm{n}}\right)$ of the polymers PBDT-PQD1, PBDT-PQD2 and PBDT-PQD3 are 113.4, 98.4 and $179.1 \mathrm{~kg} \mathrm{~mol}{ }^{-1}$ with PDIs of 2.5, 3.6 and 3.2, respectively. The relatively high molecular

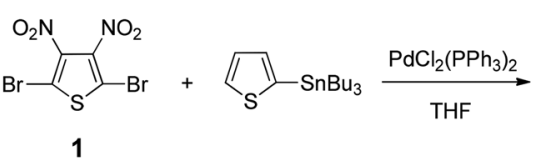<smiles>O=[N+]([O-])c1c(-c2cccs2)sc(-c2cccs2)c1[N+](=O)[O-]</smiles>

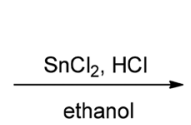

ethanol

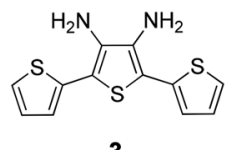

3
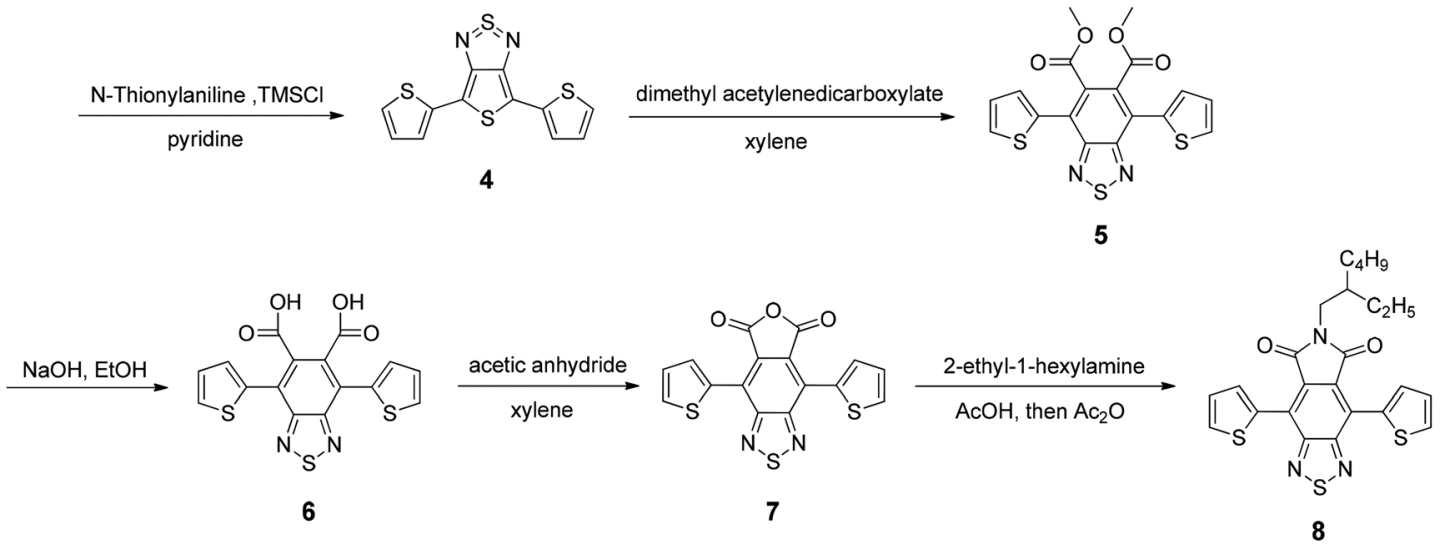
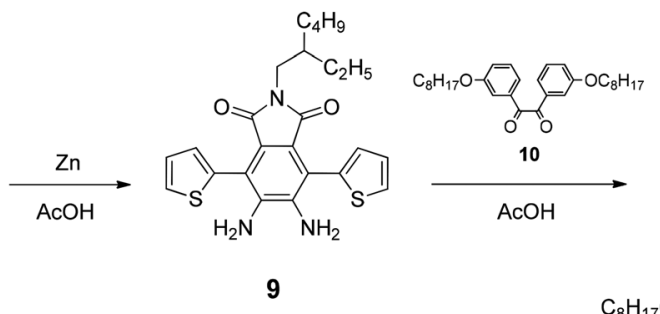<smiles>CCCN1C(=O)c2c(c(-c3cccs3)c(N)c(N)c2-c2cccs2)C1=O</smiles>

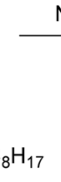

11

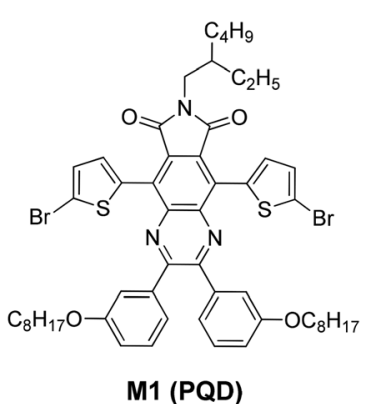

Scheme 2 Synthetic routes to the monomers. 


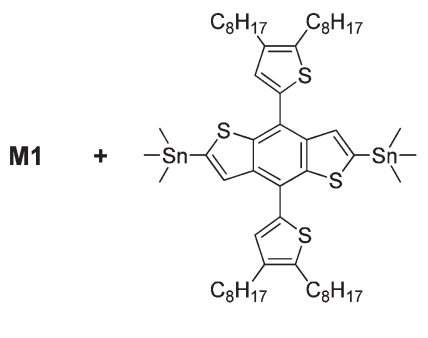

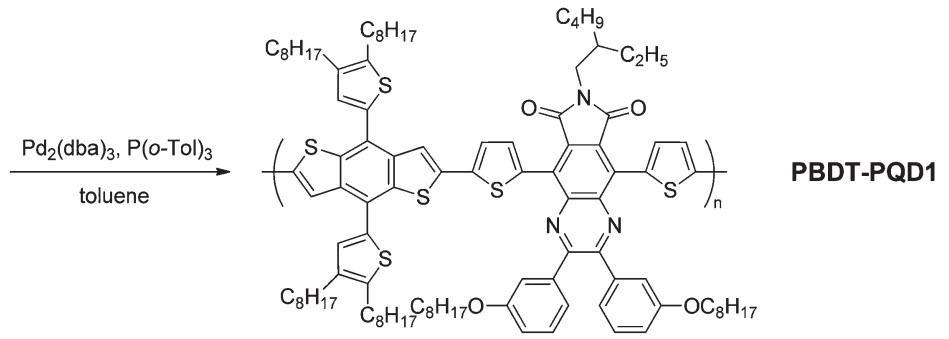<smiles>CCC(C)Cc1ccc(-c2c3cc([Si](C)(C)C)sc3c(-c3ccc(CC(C)C)s3)c3cc([Sn](C)(C)C)sc23)s1</smiles>

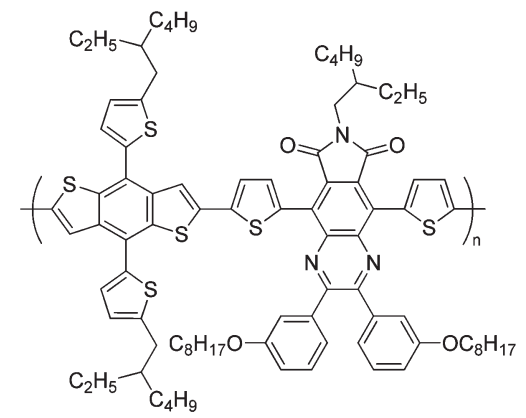

PBDT-PQD2

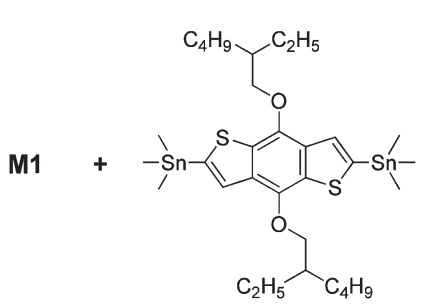

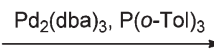

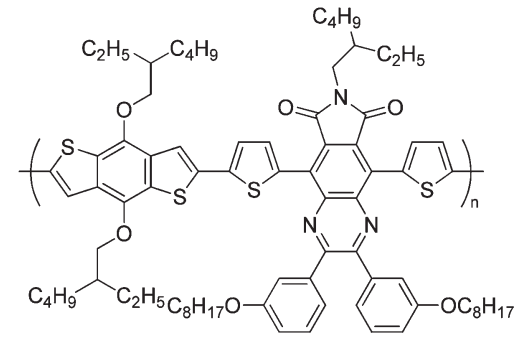

M4<smiles>C[Si](C)(C)c1ccc([Si](C)(C)C)s1</smiles>

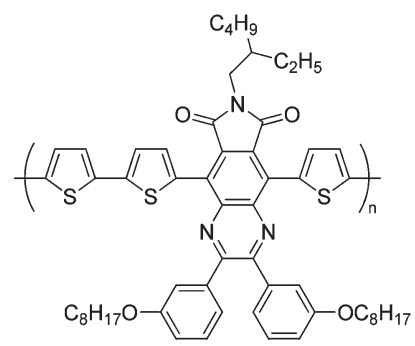

PT-PQD

Scheme 3 Synthetic routes to the four copolymers.

weights of these three copolymers are possibly ascribed to the sufficient solubility from the 2,3-bis(3-(octyloxy)phenyl) side groups on the PQD moiety and high purity of both $\mathrm{D}$ and A monomers. The copolymer PT-PQD shows a lower $M_{\mathrm{n}}$ of $30.9 \mathrm{~kg} \mathrm{~mol}{ }^{-1}$ with a broad PDI of 4.3 , owing to its relatively lower molecular weight in each segment of the backbone. As for this case, the 2,5-bis(trimethylstannyl)thiophene possesses somewhat less polymeric activity compared to the bis(trimethylstannyl)-BDT analogues. All of the copolymers are readily soluble in chlorinated solvents such as chloroform and $o$-dichlorobenzene $(o \mathrm{DCB})$, as well as in some non-chlorinated solvents like tetrahydrofuran (THF) and toluene.

\section{Absorption spectra}

The optical properties of the four copolymers were measured by UV-Vis spectroscopy both in chloroform solution and in the solid state. The normalized UV-Vis absorption spectra of the four copolymers are shown in Fig. 1. The absorption peaks $\left(\lambda_{\max }\right)$, the absorption coefficients $\left(\varepsilon_{\max }\right)$ in solution and the optical band gaps $\left(E_{\mathrm{g}}^{\mathrm{opt}}\right)$ are summarized in Table 1 . All of the polymers show two distinct absorption bands in the wavelength range of 300-450 and 500-800 nm, corresponding to the $\pi-\pi^{*}$ transition and intramolecular charge transfer (ICT) between the D/A moieties. When going from the solution to 

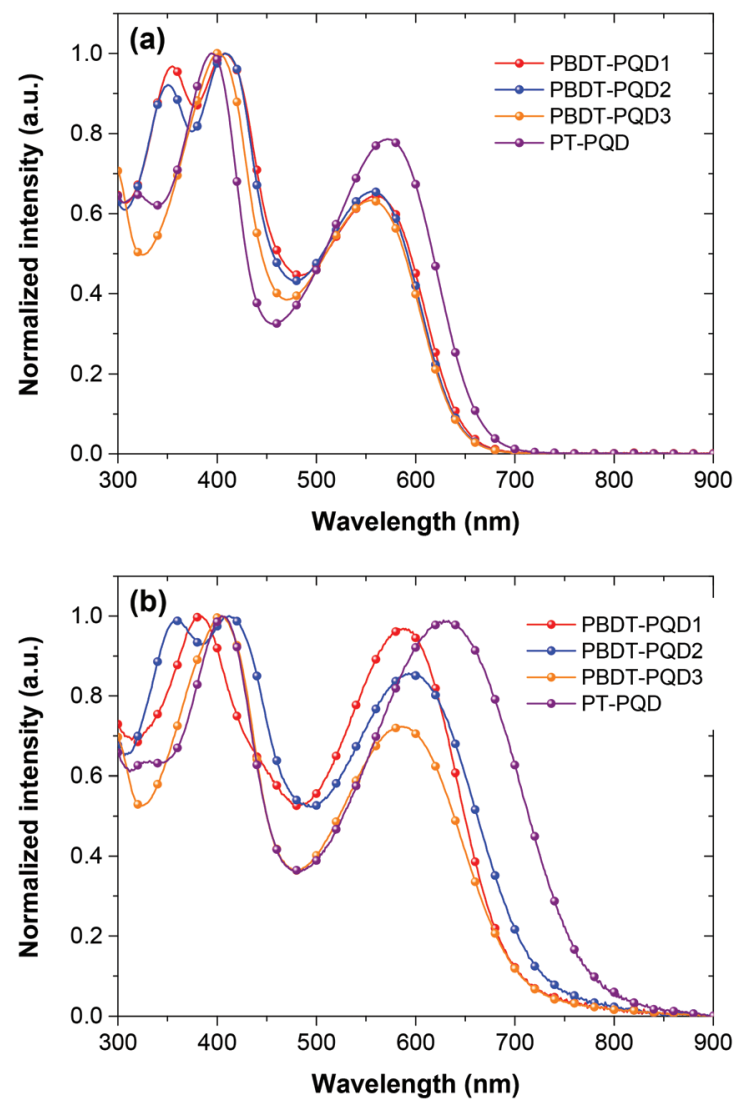

Fig. 1 Normalized UV-Vis absorption spectra of the four copolymers (a) in chloroform solution; (b) in the solid state.

the solid state, the absorption of all the four copolymers show a large red-shift, indicating that strong $\pi-\pi$ stacking occurred in the films. Compared to the copolymer PBDT-PQD3, somewhat stronger absorption intensities from the copolymers PBDT-PQD1and PBDT-PQD2 are observed in the long wavelength region. This can be attributed to an enhanced $\pi-\pi$ interaction between the copolymer chains, which originates from the vertically extended conjugation as a result of replacing the alkoxyl group with an alkylthienyl group on the BDT unit. It appears that the $\pi$-electrons are better delocalized upon introducing this $2 \mathrm{D}$ conjugated structure. ${ }^{38,56}$ The side chains on the pendant thiophene rings could alter the torsion angles between the alkylthienyl groups and the backbone, which in turn alters the $\pi-\pi$ interaction of the copolymers. As a result, PBDT-PQD2 shows a slightly red-shifted absorption spectrum in the solid state compared to PBDT-PQD1. The absorption spectra of these three copolymers are more red-shifted to the low energy region in comparison with the copolymers PBDTQx and PBDT-TPD. ${ }^{33,38}$ The enhanced intramolecular change transfer between electron-rich and deficient units result from the introduction of the stronger electron-deficient PQD units. The optical band gaps deduced from the absorption edges of the solid films are estimated to be around $1.62-1.64 \mathrm{eV}$. The absorption spectrum of copolymer PT-PQD shows an obvious red-shift compared to the other three BDT-based copolymers due to the planar backbone introduced by the terthiophene, ${ }^{29,31}$ which exhibits a lower $E_{\mathrm{g}}^{\text {opt }}$ of $1.52 \mathrm{eV}$.

\section{Electrochemical properties}

As shown in Fig. 2, square-wave voltammetry (SWV) was used to determine the oxidation $\left(\varphi_{\mathrm{ox}}\right)$ and reduction $\left(\varphi_{\mathrm{red}}\right)$ potentials of the four copolymers. We have found that SWV measurements are more sensitive, enabling clearer voltammograms of oxidation and reduction to be obtained, while it is hard to detect the reduction circles of the four copolymers from cyclic voltammetry (CV) measurements. Compared to CV measurements, the use of peaks instead of onsets in SWV measurements has been proposed to be a more accurate method of determining the energy levels of conjugated polymers. ${ }^{29,57}$ Here, the HOMO and LUMO levels were estimated from the peak potentials in SWV measurements by setting the oxidative peak potential of $\mathrm{Fc} / \mathrm{Fc}^{+}$vs. the normal hydrogen electrode (NHE) to $0.63 \mathrm{~V}^{58}$ and the NHE $v$ s. the vacuum level to $4.5 \mathrm{~V} .^{59}$ The energy levels were calculated according to the formula: HOMO $=-\left(E_{\text {ox }}+5.13\right) \mathrm{eV}$ and LUMO $=-\left(E_{\text {red }}+5.13\right) \mathrm{eV}$, where $E_{\mathrm{ox}}$ and $E_{\text {red }}$ were determined from the oxidation and reduction peaks, respectively. ${ }^{57}$ The copolymers PBDT-PQD1 and PBDT-PQD2 feature slightly lower HOMO levels of -5.97 and $-5.96 \mathrm{eV}$, compared to that of copolymer PBDT-PQD3 at -5.82 eV. Since the alkylthienyl side group has a weaker electrondonating ability in comparison with the alkyoxy side group, ${ }^{60}$ the alkylthienyl side group helps in decreasing the HOMO

Table 1 Optical and electrochemical properties of the copolymers

\begin{tabular}{|c|c|c|c|c|c|c|c|}
\hline \multirow[b]{3}{*}{ Polymer } & \multicolumn{5}{|c|}{ UV-Vis absorption spectra } & & \\
\hline & \multicolumn{2}{|l|}{ Solution } & \multicolumn{3}{|l|}{ Film } & \multicolumn{2}{|l|}{ SWV } \\
\hline & $\lambda_{\max }{ }^{a}(\mathrm{~nm})$ & $\begin{array}{l}\varepsilon_{\max }^{b} \\
\left(\mathrm{Lg}^{-1} \mathrm{~cm}^{-1}\right)\end{array}$ & $\lambda_{\max }^{c}(\mathrm{~nm})$ & $\begin{array}{l}\lambda_{\text {onset }} \\
(\mathrm{nm})\end{array}$ & $\begin{array}{l}E_{\mathrm{g}}^{\mathrm{opt} d} \\
(\mathrm{eV})\end{array}$ & $\begin{array}{l}\text { HOMO } \\
(\mathrm{eV})\end{array}$ & $\begin{array}{l}\text { LUMO } \\
(\mathrm{eV})\end{array}$ \\
\hline PBDT-PQD1 & 407,560 & 34.6 & 382,593 & 755 & 1.64 & -5.97 & -3.79 \\
\hline PBDT-PQD2 & 408,557 & 32.4 & 412,593 & 773 & 1.62 & -5.96 & -3.74 \\
\hline PBDT-PQD3 & 400,555 & 28.3 & 402,584 & 755 & 1.64 & -5.82 & -3.72 \\
\hline PT-PQD & 394,574 & 39.7 & 404,628 & 816 & 1.52 & -5.83 & -3.83 \\
\hline
\end{tabular}

${ }^{a}$ Absorption maximum in chloroform solution. ${ }^{b}$ Measured from the peak at long wavelengths. ${ }^{c}$ Absorption maximum in the film. ${ }^{d}$ Optical band gap. 


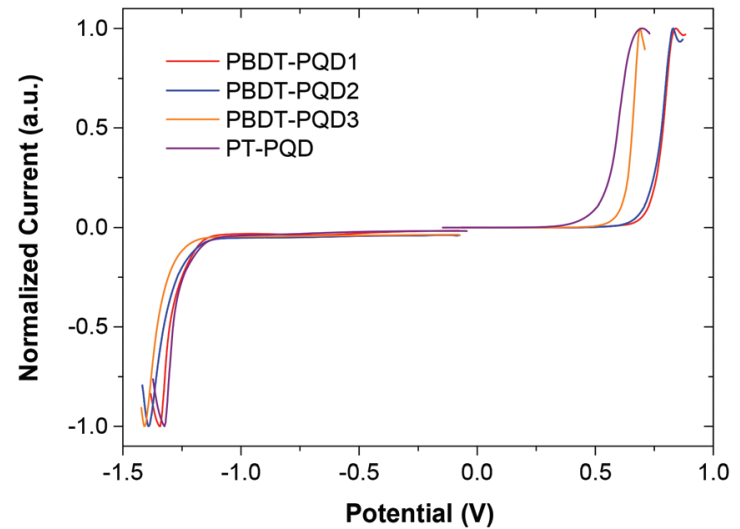

Fig. 2 Square wave voltammograms (SWV) of the four copolymers.

level of the PQD-based copolymer. The LUMO levels of these three copolymers are around $-3.7 \mathrm{eV}$. For copolymer PT-PQD, a lower-lying LUMO level and a lower band gap are observed. We also summarized the HOMO levels of the four copolymers from cyclic voltammetry (CV) measurements (Fig. S2 and Table S1 $\dagger$ ). The HOMO levels of the four copolymers follow the same trend both in the SWV and CV measurements.

In order to compare the PQD copolymers with the Qx and TPD based copolymers in the literature, the energy levels of the PQD, Qx,,$^{17,38,39,61} \mathrm{TPD}^{31-33,37,40-42}$ based copolymers and $\mathrm{PC}_{71} \mathrm{BM}^{62}$ are depicted together in Fig. 3. It should be noted that both the SWV and CV measurements were used to determine the HOMO and LUMO levels of the copolymers in Fig. 3, which explains some of the differences in the energy levels. Moreover, in some cases, since no clear reduction voltammograms were detected from CV measurements, the LUMO levels were derived by deducting the $E_{\mathrm{g}}^{\mathrm{opt}}$ values from the corresponding HOMO levels. However, as optical band gap and CV
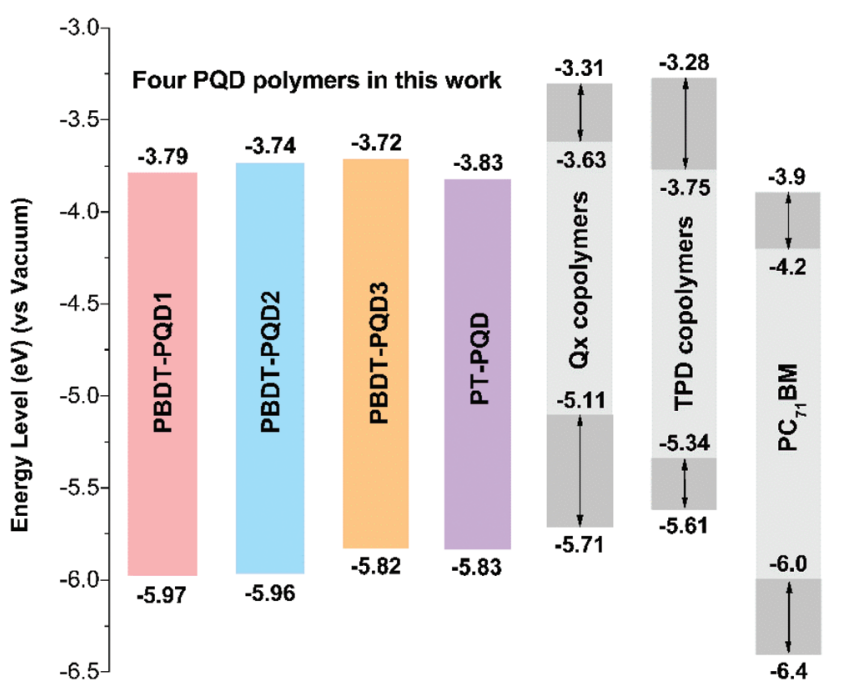

Fig. 3 Energy level diagram of the PQD, Qx and TPD based copolymers. measurements differ in terms of the electronic transitions that are measured, the optical and electrochemical band gaps should not converge. For these reasons, a range of HOMO and LUMO levels have been summarized rather than specific values. According to the energy level diagram depicted in Fig. 3, four PQD-based copolymers show relatively low-lying. HOMO and LUMO levels in comparison with the Qx and TPD based copolymers. This is consistent with the fact that the PQD moiety is more strongly electron-deficient. As the $V_{\text {oc }}$ of PSC is positively correlated with the energy difference between the HOMO level of the electron donor and the LUMO level of the electron acceptor, the lower-lying HOMO levels of the PQDbased copolymers should result in increased $V_{\text {oc }}$ values.

\section{Photovoltaic properties}

To investigate the photovoltaic properties of the four copolymers, BHJ polymer solar cells with a device configuration of ITO/PEDOT:PSS/polymer:PC ${ }_{71} \mathrm{BM} / \mathrm{LiF} / \mathrm{Al}$ were fabricated. The measurements of photovoltaic performances were carried out under an illumination of AM1.5G simulated solar light at an intensity of $100 \mathrm{~mW} \mathrm{~cm} \mathrm{~cm}^{-2}$. The optimized results were obtained via varying polymer: $\mathrm{PC}_{71} \mathrm{BM}$ weight ratios, active layer thicknesses, thermal annealing conditions and solvent additives. The corresponding PSC parameters (short-circuit current density $J_{\mathrm{sc}}, V_{\mathrm{oc}}$, fill factor FF and PCE) are included in Table 2. The $J-V$ curves are shown in Fig. 4(a). As anticipated, all the PSCs based on these four copolymers feature large $V_{\mathrm{oc}} \mathrm{S}$ of around $1.0 \mathrm{~V}$, while the PSCs based on the copolymers PBDT-Qx and PBDT-TPD exhibited slightly lower $V_{\mathrm{oc}} \mathrm{s}$ between 0.8 and $0.9 \mathrm{~V}^{3}{ }^{31-33,38}$ Among the three PBDT-PQD(1-3) copolymers, the PBDT-PQD1 based device displays a $V_{\text {oc }}$ of $0.98 \mathrm{~V}$ and a superior $J_{\mathrm{sc}}$ of $10.4 \mathrm{~mA} \mathrm{~cm}{ }^{-2}$, which results in a PCE of $4.9 \%$. There is a simultaneously high $V_{\text {oc }}$ and PCE value for a medium band gap polymer. Since these three copolymers have comparable absorption ranges in thin films, the enhanced $J_{\mathrm{sc}}$ from the copolymer PBDT-PQD1 could be partially ascribed to its higher absorption coefficient (Table 1). The copolymer PBDT-PQD2 recorded a $V_{\text {oc }}$ as high as $1.08 \mathrm{~V}$ with a comparatively high PCE of $3.5 \%$, which is rarely observed from medium band gap $(<1.65 \mathrm{eV})$ copolymers. ${ }^{63}$ For copolymer PBDT-PQD3, although the $V_{\text {oc }}$ value is $1.03 \mathrm{~V}$, the efficiency is compromised by the lower $J_{\mathrm{sc}}$ and $\mathrm{FF}$ values. On the other hand, the polymer PT-PQD has a relatively red-shifted absorption, but it gives a low $J_{\mathrm{sc}}$ and $\mathrm{FF}$ which results in an inferior

Table 2 Photovoltaic parameters of the optimized PSCs

\begin{tabular}{lllllll}
\hline Polymer & Ratio $^{a}$ & $\begin{array}{l}d^{b} \\
(\mathrm{~nm})\end{array}$ & $V_{\mathrm{oc}}(\mathrm{V})$ & $\begin{array}{l}J_{\mathrm{sc}} \\
\left(\mathrm{mA} \mathrm{cm}{ }^{-2}\right)\end{array}$ & FF & $\begin{array}{l}\text { PCE } \\
(\%)\end{array}$ \\
\hline PBDT-PQD1 & $1: 3$ & 90 & 0.98 & 10.4 & 0.48 & 4.9 \\
PBDT-PQD2 & $1: 3$ & 90 & 1.08 & 7.6 & 0.43 & 3.5 \\
PBDT-PQD3 & $1: 3$ & 90 & 1.03 & 7.3 & 0.39 & 2.9 \\
PT-PQD & $1: 3$ & 85 & 1.00 & 7.7 & 0.38 & 2.9
\end{tabular}

${ }^{a}$ Polymer : $\mathrm{PC}_{71} \mathrm{BM}$ weight ratio. ${ }^{b}$ Active layer thickness $(d)$. 

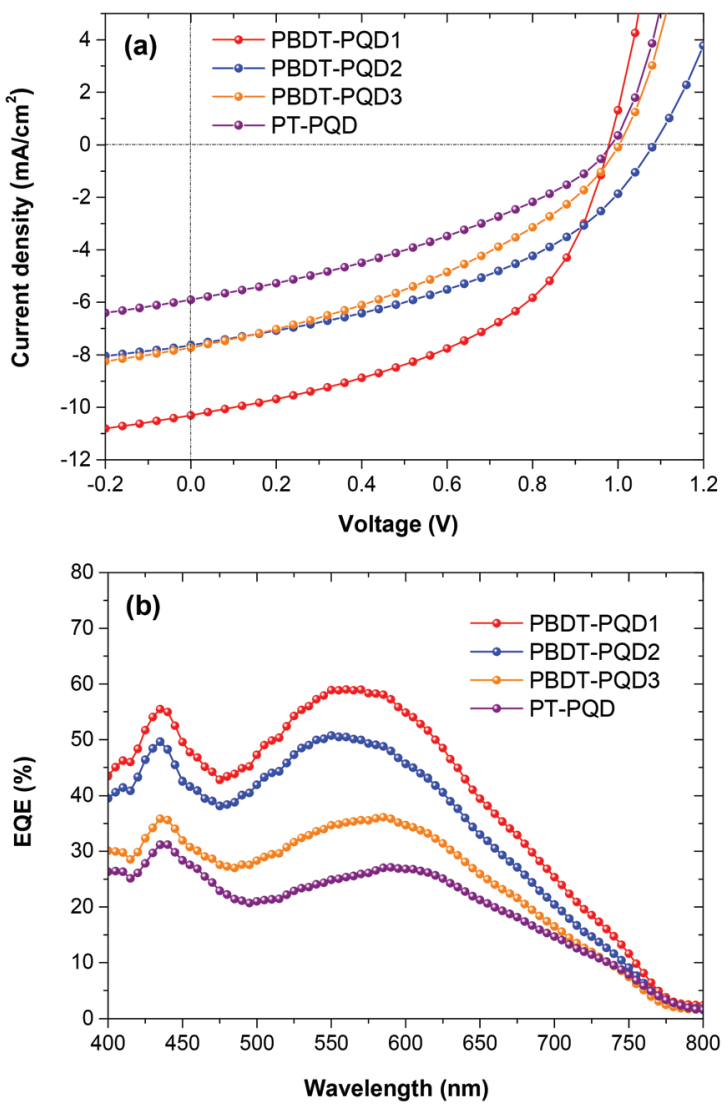

Fig. 4 (a) Current density-voltage characteristics of the four copolymer: $P C_{71} \mathrm{BM}$ solar cells; (b) external quantum efficiency (EQE) spectra measured under illumination of monochromatic light.
PCE. For the four copolymers, thermal annealing and the use of the solvent additive 1,8-diiodooctane show no positive effect on the device performance.

As depicted in Fig. 4(b), external quantum efficiencies (EQE) were measured to evaluate the photoresponse of the PSCs. All the EQE curves are consistent with the corresponding absorption spectra in the $400-800 \mathrm{~nm}$ region, while the copolymer PT-PQD demonstrates a red-shifted EQE curve compared to the copolymers PBDT-PQD(1-3). Among the four copolymers, the devices based on PBDT-PQD1 show the highest photo conversion efficiency, indicating more charge collection and less charge recombination at the junction between the polymer and $\mathrm{PC}_{71} \mathrm{BM}$, which is consistent with its $J-V$ results. Integration of the EQE spectra with the AM1.5G solar spectrum affords the calculated $J_{\mathrm{sc}}$ values of 10.1, 7.1, 6.9 and $7.0 \mathrm{~mA}$ $\mathrm{cm}^{-2}$, respectively, which are in agreement with the $J_{\mathrm{sc}}$ from the $J-V$ results.

\section{Film morphology}

AFM measurements were carried out to study the surface morphology of the blend layers. As shown in Fig. 5, topographic images were taken from the films of the polymer $/ \mathrm{PC}_{71} \mathrm{BM}$ (1:3, w/w) blends. For copolymers PBDT-PQD2, PBDT-PQD3 and PT-PQD, each of the blended films form a very uniform and smooth surface of the D/A components with small rootmean-square (RMS) roughness values of $0.23,0.26$, and $0.25 \mathrm{~nm}$, respectively. For copolymer PBDT-PQD1, the RMS roughness slightly increases to $0.53 \mathrm{~nm}$, while the development of small nanostructures and fine phase separation is obtained. To probe the morphology throughout the active
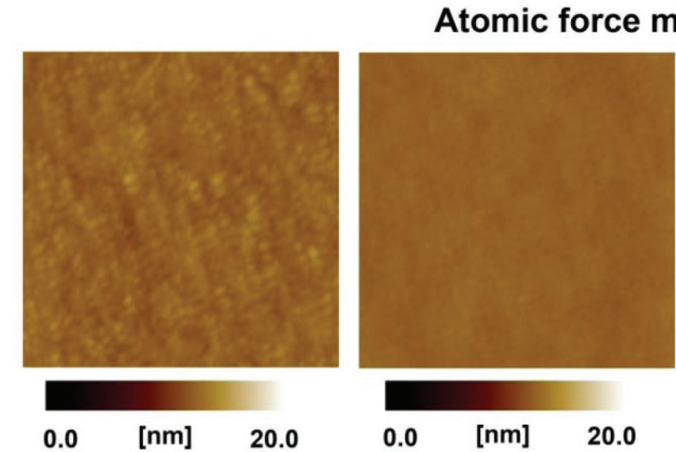

\section{icroscopy (AFM)}
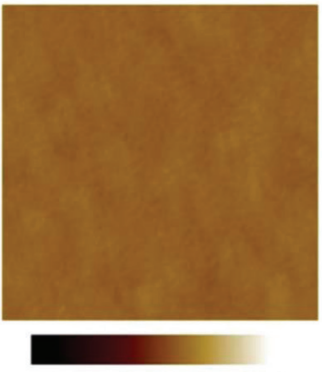

$0.0 \quad[\mathrm{~nm}] \quad 20.0$

Transmission electron microscopy (TEM)

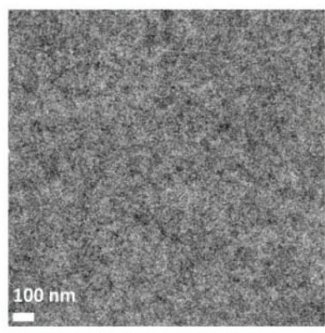

(a) PBDT-PQD1:PC71BM (b)

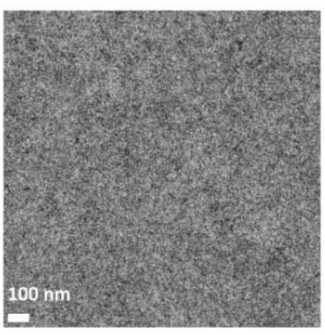

(b) PBDT-PQD2:PC71BM

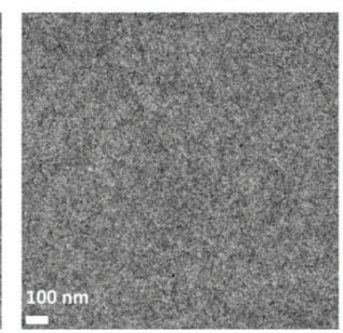

(c) PBDT-PQD3:PC71BM
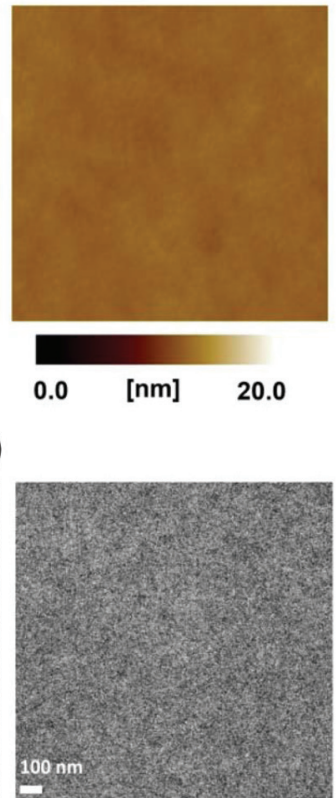

(d) PT-PQD:PC $71 B M$

Fig. 5 AFM topography $\left(2 \times 2 \mu \mathrm{m}^{2}\right)$ and TEM bright field images of the optimized polymer:PC ${ }_{71} B M$ blended films. 
layers, TEM was employed to investigate the real-space structures of the polymer $/ \mathrm{PC}_{71} \mathrm{BM}$ blends. In the TEM images, the dark areas are attributed to the $\mathrm{PC}_{71} \mathrm{BM}$-rich domains, owing to their higher electron scattering density than the conjugated polymers. As shown in Fig. 5, each of the blend film forms fine phase separation without large $\mathrm{PC}_{71} \mathrm{BM}$ aggregates. The widths of the domains are smaller than the typical exciton diffusion length $(\sim 10 \mathrm{~nm})$, indicating that excitons can efficiently diffuse to the D/A interface to dissociate. On the basis of both the AFM and TEM topography, it is evident that the different building blocks and side chain modulations on the PQD-based copolymers have a limited impact on the film morphology of the polymer/ $\mathrm{PC}_{71} \mathrm{BM}$ blends. All the polymers can form favorable phase separation in films with $\mathrm{PC}_{71} \mathrm{BM}$ as the acceptor.

\section{Conclusion}

In conclusion, four $\mathrm{D}-\mathrm{A}$ copolymers based on the new electron-deficient unit PQD were synthesized and characterized. Compared to the Qx and TPD units, the PQD moiety consisting of a fused quinoxaline and dicarboxylic imide structure exhibits a more electron-deficient nature. The alkyl side chain pattern of the PQD unit enables the four copolymers to have good solubility at very high molecular weights. Introduction of the dicarboxylic imide fused onto the Qx motif has been found to obtain medium band gaps and lower both the HOMO and LUMO levels. As anticipated, the PSCs based on these four polymers generate very high $V_{\mathrm{oc}} \mathrm{s}$ of around $1.0 \mathrm{~V}$. The aromatic side chain pattern of the BDT units shows a rational influence on the absorption intensity and HOMO levels of copolymers PBDT-PQD(1-3), which is correlated with the device performance. As a consequence, the PBDT-PQD1:PC ${ }_{71} \mathrm{BM}$ solar cell attains a superior photocurrent and a PCE of $4.9 \%$ in a standard solar cell configuration without the need for thermal annealing or the addition of solvent additives. Although high $V_{\text {oc }}$ values have been reported for some high band gap copolymers, it is striking to observe a medium band gap $(<1.65 \mathrm{eV})$ copolymer obtaining a very high $V_{\text {oc }}$ of around $1.0 \mathrm{~V}$ with a high PCE of around 5\%. The polymer PBDT-PQD2 displayed a decent PCE of $3.5 \%$ with a particularly high $V_{\text {oc }}$ of $1.08 \mathrm{~V}$, which represents one of the highest $V_{\mathrm{oc}} \mathrm{S}$ achieved by PSCs based on $\mathrm{PC}_{71} \mathrm{BM}$ as the acceptor. We have demonstrated that the PQD moiety is a promising electron-deficient building block for obtaining efficient photovoltaic materials with high $V_{\text {oc }}$. The discussed structure-property correlations also validate the proposed design strategy of combining two electronwithdrawing units to afford a stronger electron-deficient arene.

\section{Acknowledgements}

We thank the Swedish Research Council, the Swedish Energy Agency and the EU projects SUNFLOWER-"SUstainable Novel FLexible Organic Watts Efficiently Reliable” (FP7-ICT-2011-7,
Grant number: 287594) for financial support. C. Wang acknowledges the China Scholarship Council for a stipend. E. Wang acknowledges the program for the Excellent Doctoral Dissertations of Guangdong Province (ybzzxm201114).

\section{Notes and references}

1 G. Dennler, M. C. Scharber and C. J. Brabec, Adv. Mater., 2009, 21, 1323-1338.

2 B. C. Thompson and J. M. J. Fréchet, Angew. Chem., Int. Ed., 2008, 47, 58-77.

3 F. C. Krebs, Sol. Energy Mater. Sol. Cells, 2009, 93, 394-412.

4 F. C. Krebs, N. Espinosa, M. Hösel, R. R. Søndergaard and M. Jørgensen, Adv. Mater., 2014, 26, 29-39.

5 G. Yu, J. Gao, J. C. Hummelen, F. Wudl and A. J. Heeger, Science, 1995, 270, 1789-1791.

6 A. J. Heeger, Chem. Soc. Rev., 2010, 39, 2354-2371.

7 M. Zhang, X. Guo, X. Wang, H. Wang and Y. Li, Chem. Mater., 2011, 23, 4264-4270.

8 H. Zhou, L. Yang and W. You, Macromolecules, 2012, 45, 607-632.

9 E. Wang, W. Mammo and M. R. Andersson, Adv. Mater., 2014, 26, 1801-1826.

10 M. Svensson, F. Zhang, S. C. Veenstra, W. J. H. Verhees, J. C. Hummelen, J. M. Kroon, O. Inganäs and M. R. Andersson, Adv. Mater., 2003, 15, 988-991.

11 A. Gadisa, W. Mammo, L. M. Andersson, S. Admassie, F. Zhang, M. R. Andersson and O. Inganäs, Adv. Funct. Mater., 2007, 17, 3836-3842.

12 F. Zhang, W. Mammo, L. M. Andersson, S. Admassie, M. R. Andersson and O. Inganäs, Adv. Mater., 2006, 18, 2169-2173.

13 N. Blouin, A. Michaud and M. Leclerc, Adv. Mater., 2007, 19, 2295-2300.

14 Z. Chen, P. Cai, J. Chen, X. Liu, L. Zhang, L. Lan, J. Peng, Y. Ma and Y. Cao, Adv. Mater., 2014, 26, 2586-2591.

15 Y. Liu, J. Zhao, Z. Li, C. Mu, W. Ma, H. Hu, K. Jiang, H. Lin, H. Ade and H. Yan, Nat. Commun., 2014, 5.

16 J. Huang, Y. Zhu, J. Chen, L. Zhang, J. Peng and Y. Cao, Macromol. Rapid Commun., 2014, 35, 1960-1967.

17 E. Wang, L. Hou, Z. Wang, S. Hellström, F. Zhang, O. Inganäs and M. R. Andersson, Adv. Mater., 2010, 22, 5240-5244.

18 D. Dang, W. Chen, S. Himmelberger, Q. Tao, A. Lundin, R. Yang, W. Zhu, A. Salleo, C. Müller and E. Wang, Adv. Energy Mater., 2014, 4, 1400680.

19 X. Xu, Z. Li, O. Bäcke, K. Bini, D. I. James, E. Olsson, M. R. Andersson and E. Wang, J. Mater. Chem. A, 2014, 2, 18988-18997.

20 W. Li, W. S. C. Roelofs, M. M. Wienk and R. A. J. Janssen, J. Am. Chem. Soc., 2012, 134, 13787-13795.

21 W. Li, K. H. Hendriks, W. S. C. Roelofs, Y. Kim, M. M. Wienk and R. A. J. Janssen, Adv. Mater., 2013, 25, 3182-3186. 
22 C. B. Nielsen and T. Bjørnholm, Org. Lett., 2004, 6, 33813384.

23 Q. T. Zhang and J. M. Tour, J. Am. Chem. Soc., 1997, 119, 5065-5066.

24 Q. T. Zhang and J. M. Tour, J. Am. Chem. Soc., 1998, 120, 5355-5362.

25 E. Wang, Z. Ma, Z. Zhang, K. Vandewal, P. Henriksson, O. Inganäs, F. Zhang and M. R. Andersson, J. Am. Chem. Soc., 2011, 133, 14244-14247.

26 Z. Ma, W. Sun, S. Himmelberger, K. Vandewal, Z. Tang, J. Bergqvist, A. Salleo, J. W. Andreasen, O. Inganäs, M. R. Andersson, C. Müller, F. Zhang and E. Wang, Energy Environ. Sci., 2014, 7, 361-369.

27 X. Xu, P. Cai, Y. Lu, N. S. Choon, J. Chen, X. Hu and B. S. Ong, J. Polym. Sci., Part A: Polym. Chem., 2013, 51, 424-434.

28 Z. F. Ma, D. F. Dang, Z. Tang, D. Gedefaw, J. Bergqvist, W. G. Zhu, W. Mammo, M. R. Andersson, O. Inganäs, F. L. Zhang and E. G. Wang, Adv. Energy Mater., 2014, 4, 1301455.

29 L. J. Lindgren, F. Zhang, M. Andersson, S. Barrau, S. Hellström, W. Mammo, E. Perzon, O. Inganäs and M. R. Andersson, Chem. Mater., 2009, 21, 3491-3502.

30 E. Wang, L. Hou, Z. Wang, Z. Ma, S. Hellström, W. Zhuang, F. Zhang, O. Inganäs and M. R. Andersson, Macromolecules, 2011, 44, 2067-2073.

31 Y. Zou, A. Najari, P. Berrouard, S. Beaupré, B. Réda Aïch, Y. Tao and M. Leclerc, J. Am. Chem. Soc., 2010, 132, 53305331.

32 C. Piliego, T. W. Holcombe, J. D. Douglas, C. H. Woo, P. M. Beaujuge and J. M. J. Fréchet, J. Am. Chem. Soc., 2010, 132, 7595-7597.

33 C. Cabanetos, A. El Labban, J. A. Bartelt, J. D. Douglas, W. R. Mateker, J. M. J. Fréchet, M. D. McGehee and P. M. Beaujuge, J. Am. Chem. Soc., 2013, 135, 4656-4659.

34 Z.-G. Zhang and Y. Li, Sci. China: Chem., 2015, 58, 192-209.

35 L. Huo and J. Hou, Polym. Chem., 2011, 2, 2453-2461.

36 P. Sista, M. C. Biewer and M. C. Stefan, Macromol. Rapid Commun., 2012, 33, 9-20.

37 T.-Y. Chu, J. Lu, S. Beaupré, Y. Zhang, J.-R. Pouliot, S. Wakim, J. Zhou, M. Leclerc, Z. Li, J. Ding and Y. Tao, J. Am. Chem. Soc., 2011, 133, 4250-4253.

38 R. Duan, L. Ye, X. Guo, Y. Huang, P. Wang, S. Zhang, J. Zhang, L. Huo and J. Hou, Macromolecules, 2012, 45, 3032-3038.

39 Y. Fu, H. Cha, S. Song, G.-Y. Lee, C. Eon Park and T. Park, J. Polym. Sci., Part A: Polym. Chem., 2013, 51, 372-382.

40 J. Yuan, Z. Zhai, H. Dong, J. Li, Z. Jiang, Y. Li and W. Ma, Adv. Funct. Mater., 2013, 23, 885-892.

41 J.-H. Kim, J. B. Park, F. Xu, D. Kim, J. Kwak, A. C. Grimsdale and D.-H. Hwang, Energy Environ. Sci., 2014, 7, 4118-4131.
42 V. Tamilavan, K. H. Roh, R. Agneeswari, D. Y. Lee, S. Cho, Y. Jin, S. H. Park and M. H. Hyun, J. Polym. Sci., Part A: Polym. Chem., 2014, 52, 3564-3574.

43 T. L. Tam, H. Li, F. Wei, K. J. Tan, C. Kloc, Y. M. Lam, S. G. Mhaisalkar and A. C. Grimsdale, Org. Lett., 2010, 12, 3340-3343.

44 H. Li, T. L. Tam, Y. M. Lam, S. G. Mhaisalkar and A. C. Grimsdale, Org. Lett., 2010, 13, 46-49.

45 E. Perzon, F. Zhang, M. Andersson, W. Mammo, O. Inganäs and M. R. Andersson, Adv. Mater., 2007, 19, 3308-3311.

46 A. P. Zoombelt, M. Fonrodona, M. M. Wienk, A. B. Sieval, J. C. Hummelen and R. A. J. Janssen, Org. Lett., 2009, 11, 903-906.

47 F. Zhang, J. Bijleveld, E. Perzon, K. Tvingstedt, S. Barrau, O. Inganäs and M. R. Andersson, J. Mater. Chem., 2008, 18, 5468-5474.

48 E. Wang, L. Hou, Z. Wang, S. Hellström, W. Mammo, F. Zhang, O. Inganäs and M. R. Andersson, Org. Lett., 2010, 12, 4470-4473.

49 Y. Dong, W. Cai, X. Hu, C. Zhong, F. Huang and Y. Cao, Polymer, 2012, 53, 1465-1472.

50 X. Hu, Y. Dong, F. Huang, X. Gong and Y. Cao, J. Phys. Chem. C, 2013, 117, 6537-6543.

51 H. Li, T. M. Koh, A. Hagfeldt, M. Gratzel, S. G. Mhaisalkar and A. C. Grimsdale, Chem. Commun., 2013, 49, 2409-2411.

52 L. Wang, D. Cai, Q. Zheng, C. Tang, S.-C. Chen and Z. Yin, ACS Macro Lett., 2013, 2, 605-608.

53 H. Li, S. Sun, S. Mhaisalkar, M. T. Zin, Y. M. Lam and A. C. Grimsdale, J. Mater. Chem. A, 2014, 2, 17925-17933.

54 C. B. Nielsen, R. S. Ashraf, N. D. Treat, B. C. Schroeder, J. E. Donaghey, A. J. P. White, N. Stingelin and I. McCulloch, Adv. Mater., 2015, 27, 948-953.

55 M. C. Ruiz Delgado, V. Hernández, J. T. López Navarrete, S. Tanaka and Y. Yamashita, J. Phys. Chem. B, 2004, 108, 2516-2526.

56 L. Huo, S. Zhang, X. Guo, F. Xu, Y. Li and J. Hou, Angew. Chem., Int. Ed., 2011, 50, 9697-9702.

57 S. Hellstrom, F. Zhang, O. Inganäs and M. R. Andersson, Dalton Trans., 2009, 10032-10039.

58 V. V. Pavlishchuk and A. W. Addison, Inorg. Chim. Acta, 2000, 298, 97-102.

59 A. J. Bard and L. R. Faulkner, Electrochemical Methods: Fundamentals and Applications, Wiley, 2000.

60 L. Huo, J. Hou, S. Zhang, H.-Y. Chen and Y. Yang, Angew. Chem., Int. Ed., 2010, 49, 1500-1503.

61 C. Bathula, C. E. Song, W.-H. Lee, J. Lee, S. Badgujar, R. Koti, I.-N. Kang, W. S. Shin, T. Ahn, J.-C. Lee, S.-J. Moon and S. K. Lee, Thin Solid Films, 2013, 537, 231-238.

62 Y. He and Y. Li, Phys. Chem. Chem. Phys., 2011, 13, 1970-1983.

63 Y.-J. Cheng, S.-W. Cheng, C.-Y. Chang, W.-S. Kao, M.-H. Liao and C.-S. Hsu, Chem. Commun., 2012, 48, 32033205. 